\title{
Oxalate nephropathy in free-living American bullfrog tadpoles
}

\author{
Toshihiro Tokiwa ${ }^{1,2}$, Sho Kadekaru' ${ }^{1}$, Masao Ito ${ }^{3}$, Makoto Yoshida ${ }^{4}$, Yumi Une ${ }^{1, *}$ \\ ${ }^{1}$ Laboratory of Veterinary Pathology, School of Veterinary Medicine, Azabu University, 1-17-71 Fuchinobe, Chuo-ku, \\ Sagamihara, Kanagawa 252-5201, Japan \\ ${ }^{2}$ Division of Pathobiological Analysis, Department of Veterinary Pathobiology, \\ Nippon Veterinary and Life Science University, 1-7-1 Kyonncho, Musashino, Tokyo 180-8602, Japan \\ ${ }^{3}$ Nagasaki Biopark, 2-9-22, Saikai, Nagasaki 300-1252, Japan \\ ${ }^{4}$ Kanagawa Agricultural Technology Center, 1617 Kamiyoshizawa, Hiratsuka, 259-1204 Japan
}

\begin{abstract}
In February 2014, wild American bullfrog Lithobates catesbeianus tadpoles from an artificial pond in the Kyusyu region, Japan, presented with coelomic and subcutaneous edema and erythema within the skin. A pathological examination of 57 tadpoles of American bullfrogs in the region was conducted to evaluate the disease. Crystal deposition of varying degrees was found in the kidneys of 35 tadpoles $(61.4 \%)$. The crystals were transparent, pleomorphic in shape, highly birefringent in polarized light, and arranged in a radial pattern within the renal tubular lumen. Using Alizarin Red S stain and liquid chromatography, these crystals were identified as calcium oxalate. Severe coelomic and subcutaneous edema was observed in 7 of these 35 tadpoles $(20.0 \%)$. Ammonia levels in coelomic fluid were extremely elevated $\left(>1000 \mu \mathrm{g} \mathrm{dl}^{-1}\right)$ in 4 tadpoles examined. These findings suggest that oxalate deposition in kidneys causes metabolic disorder with renal nephropathy. The source of the oxalate could not be determined; however, the presence of calcium oxalates in pond sediments, as revealed by liquid chromatography, suggested that the deposition was most likely due to ingestion of oxalate materials from the environment. This is the first report of oxalate nephropathy in free-living amphibians.
\end{abstract}

KEY WORDS: Lithobates catesbeianus $\cdot$ Edema $\cdot$ Renal oxalosis $\cdot$ Oxalate poisoning $\cdot$ Calcium oxalate $\cdot$ Japan

\section{INTRODUCTION}

Renal oxalosis in animals is most frequently caused by ethylene glycol poisoning, ingestion of oxalatecontaining plants, or ingestion of plants colonized by oxalate-producing fungi (Sanz \& Reig 1992, Rahman et al. 2013). In amphibians, there are a few reports of renal oxalosis in captive-bred tadpoles and frogs consuming oxalate-rich plants or crickets that fed on oxalate-containing plants (Wright 2001). In this study, we found oxalate poisoning in free-living tadpoles of American bullfrogs Lithobates catesbeianus from the Kyusyu region, Japan. Severe coelomic and subcutaneous edema and nephropathy were observed in affected tadpoles, and they had features that appeared to be associated with renal nephropathy and metabolic disorder. Since the pathological features and pathogenesis of renal poisoning in tadpoles have not been characterized, the aim of the present study was to further investigate the features of this disorder, including gross renal pathological and histopathological changes. To our knowledge, this is the first report of oxalate nephropathy in freeliving amphibians. 


\section{MATERIALS AND METHODS}

\section{Study area and tadpole evaluation}

A total of 68 free-living American bullfrog tadpoles were examined between February and March 2014 (Table 1). These included 57 tadpoles caught in an artificial pond (pond A) in a zoological garden located in the Kyusyu region, and 11 tadpoles from another artificial pond (pond B) in the same zoological garden as a normal control group. These ponds were natural breeding grounds of American bullfrogs. Pond B was closely situated to, but located upstream of, pond A. Pond A contained large amounts of sediment containing fallen leaves and mud, whereas there was little sediment in pond B. All animal experiments in this study were carried out with permission from the Ministry of Environment (121221300) and in accordance with the Japanese Law of Animal Welfare and Care.

The tadpoles were euthanized using FA100 (Tamura-seiyaku) and necropsied. For the detection of ranavirus, DNA was extracted from the left kidney, spleen, and a part of the liver of the tadpoles using NucleoSpin ${ }^{\circledR}$ Tissue (Takara Bio), and polymerase chain reaction (PCR) was performed according to the protocol described by Marsh et al. (2002). For histopathology, visceral organs were fixed in $10 \%$ neutral buffered formalin. The tissues were embedded in paraffin, sectioned at a thickness of $3 \mu \mathrm{m}$ and stained with hematoxylin and eosin (H\&E). Sections were examined under polarized light for birefringence. In order to identify calcium oxalate, sections were stained with Alizarin Red S at pH 7.0 and 4.2, and insolubility was determined in $0.1 \mathrm{~N}$ hydrochloric acid ( $\mathrm{HCl}$ ) and $2 \mathrm{M}$ acetic acid, as described by Proia \& Brinn (1985). Coelomic fluids were aseptically collected from 4 tadpoles with severe coelomic edema and analyzed using the FUJI DRI-CHEM 7000 Veterinary Chemistry Analyzer (Fujifilm) through regular laboratory methods. Coelomic fluids from other tadpoles were not collected because their coelomic cavities contained no fluid.

\section{Determination of oxalate concentration}

One-step analysis using high-performance liquid chromatography (HPLC) was carried out on the soluble oxalate contents in tadpole kidneys and environmental samples (mud and fallen leaves) from pond A. The kidneys were collected from 7 tadpoles with severe coelomic and subcutaneous edema and directly
Table 1. Prevalence of coelomic and subcutaneous edema and crystal deposition in the kidneys of American bullfrog Lithobates catesbeianus tadpoles; nr: not recorded

\begin{tabular}{|lcccc|}
\hline Date & Pond & \multicolumn{4}{c|}{ Number of tadpoles } & \multicolumn{2}{c|}{$\begin{array}{c}\text { With } \\
\text { edema }\end{array}$} & $\begin{array}{c}\text { With crystal } \\
\text { deposition }\end{array}$ \\
\hline 20 Feb 2014 & A & 10 & 3 & 9 \\
17 Mar 2014 & A & 18 & $n r$ & 12 \\
13 Feb 2014 & A & 29 & 4 & 14 \\
13 Feb 2014 & B & 11 & 0 & 0 \\
\hline
\end{tabular}

homogenized together with $2 \mathrm{ml}$ of deionized water for $1 \mathrm{~min}$. The homogenates were centrifuged at 500 $\times g$ for $10 \mathrm{~min}$, and these supernatants were centrifuged at $8000 \times g$ for $10 \mathrm{~min}$. Mud (50 g) and fallen leaves (20 mg) were collected from pond A in March 2014 and preserved at $-30^{\circ} \mathrm{C}$ until use. The frozen mud from pond A was directly homogenized for 15 min. Defrosted frozen leaves from pond A were homogenized together with $10 \mathrm{ml}$ of deionized water for $1 \mathrm{~min}$. The supernatants of homogenates were immediately filtered through filter paper. The filtrates were further filtered using a spin column Ultrafree-MC $0.45 \mu \mathrm{m}$ PTF membrane (Millipore) and centrifuged at $4000 \times g$ for $30 \mathrm{~min}$. HPLC analysis was performed using the Shim-pack SCR-102H column (Shimadzu) in the LC-10A system (Shimadzu) with $5 \mathrm{mM}$ p-toluenesulfonic acid as the dissociate

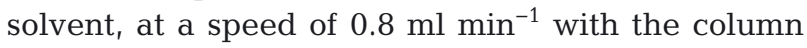
temperature at $40^{\circ} \mathrm{C}$.

\section{RESULTS}

Of the 57 tadpoles from pond A, 4 (12.3\%) appeared to have obvious abdominal distension on the body with hemorrhages within the skin when captured (Fig. 1). At necropsy, severe coelomic and/or subcutaneous edema were seen in 7 of 57 (12.3\%) tadpoles from pond A. Kidney enlargement and multifocal white renal calculi in the kidney (Fig. 2) were seen at gross examination in 19 of 57 (33.3\%) tadpoles from pond $\mathrm{A}$. The other tadpoles from pond $\mathrm{A}$ and 11 tadpoles from pond B were macroscopically normal. Ranavirus was not identified in the kidney, spleen, or liver from the 68 tadpoles.

On histopathological examination, crystal deposition was found in the kidneys of 35 of 57 (61.4\%) tadpoles from pond A (Table 1). Minor crystal deposition, characterized by a few small crystals, detectable only under polarized light, occurred in 10 of 35 $(28.6 \%)$, moderate crystal deposition was present in 

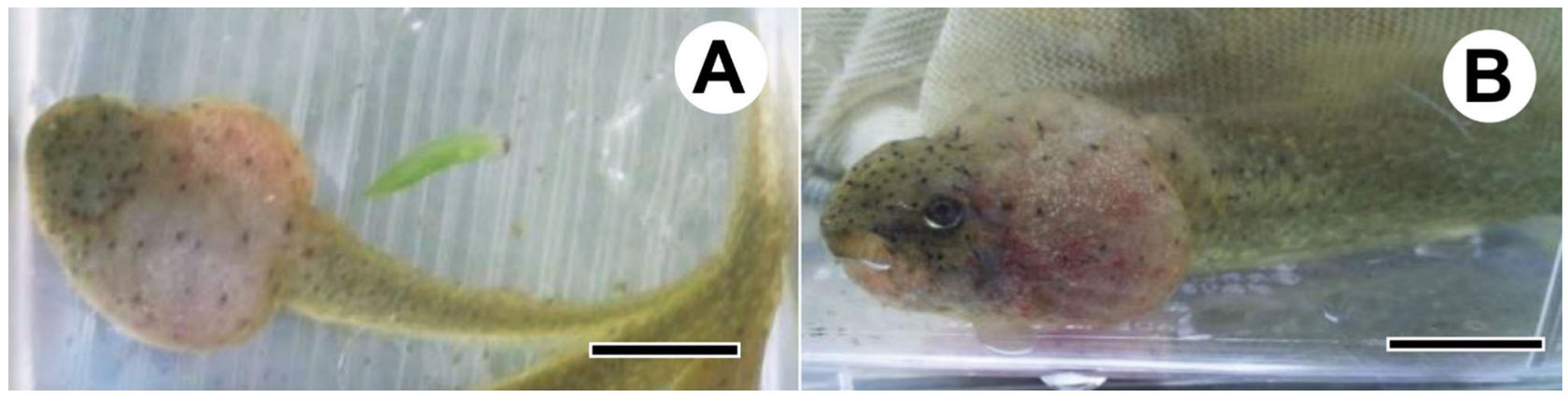

Fig. 1. Live American bullfrog Lithobates catesbeianus tadpole with hemorrhages within the skin, and abdominal distension. (A) Dorsal and (B) lateral view. Scale bar $=2 \mathrm{~cm}$

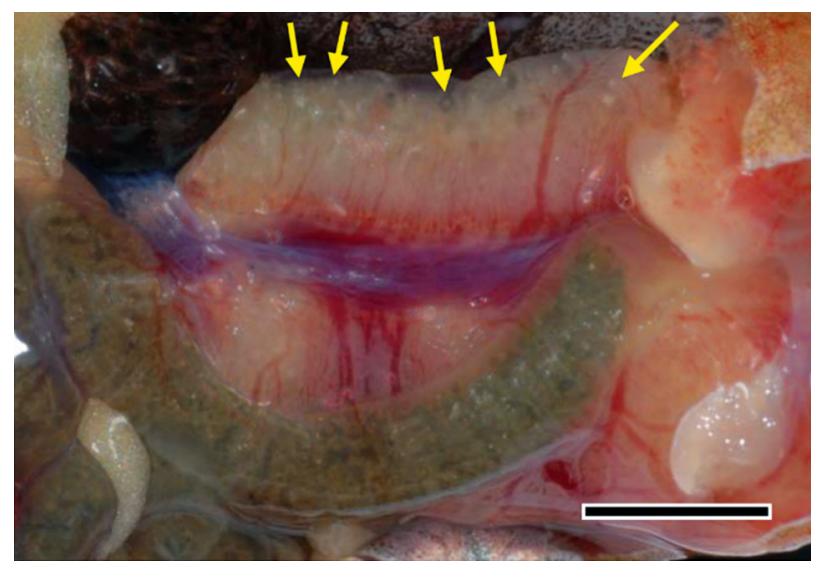

Fig. 2. Enlarged kidney of an American bullfrog Lithobates catesbeianus tadpole with abdominal and subcutaneous edema showing multifocal white renal calculi in the kidney (arrows). Scale bar $=5 \mathrm{~mm}$

18 of $35(51.4 \%)$, and severe crystal deposition scattered throughout histological sections was seen in 7 of $35(20 \%)$ tadpoles. The crystals were found mostly in renal tubules that were irregularly dilated by these crystals (Fig. 3A), and the tubular epithelium showed flattening or necrosis with hyaline droplet degeneration. No crystal depositions were observed in the kid- ney of 11 tadpoles from pond B and within the other organs of all tadpoles examined.

The crystals were transparent, pleomorphic in shape, highly birefringent in polarized light, and arranged in a radial pattern within the renal tubular lumen (Fig. 3B). Thorough fixation and routine processing did not result in dissolution of these crystals. The crystals stained positively with Alizarin Red S at a pH 7.0 (Fig. 3C) but not at $\mathrm{pH} 4.2$, and they were soluble in $0.1 \mathrm{~N}$ hydrochloric acid but insoluble in $2 \mathrm{M}$ acetic acid.

The biochemistry of coelomic fluid from 4 tadpoles with edema and severe crystal deposition in the kidneys is shown in Table 2. The ammonia levels in the coelomic fluid were high in these tadpoles. In HPLC analyses, the chromatograms showed oxalic acid peaks in the kidneys, mud, and fallen leaves, with concentrations of $0.35,0.02$, and $0.02 \mathrm{mg} \mathrm{g}^{-1}$, respectively.

\section{DISCUSSION}

The morphological characters of crystal deposition in the kidneys of the tadpoles and their birefringence
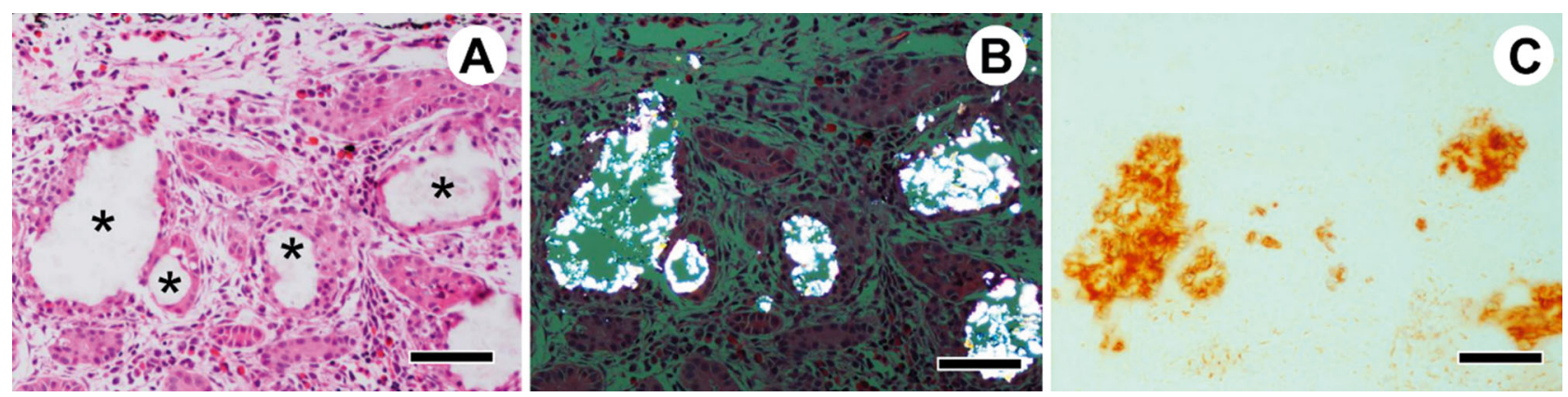

Fig. 3. Crystalline deposits in the kidney of an American bullfrog Lithobates catesbeianus tadpole. (A) Dilated renal tubules containing crystalline deposits (asterisks). H\&E stain. (B) Crystals are doubly retractile with polarized light. H\&E stain.

(C) Crystals are positively stained with Alizarin Red S stain at pH 7.0. Scale bar $=50 \mu \mathrm{m}$ 
Table 2. Biochemistry of coelomic fluid from 4 affected bullfrog Lithobates catesbeianus tadpoles

\begin{tabular}{|lccccc|}
\hline & \multirow{2}{*}{ Unit } & \multicolumn{4}{c|}{ Tadpole } \\
\cline { 3 - 6 } & & No. 1 & No. 2 & No. 3 & \multirow{2}{*}{ No. 4 } \\
\hline Creatinine & $\mathrm{mg} \mathrm{dl}^{-1}$ & 0.53 & 0.27 & 0.33 & 0.42 \\
Urea nitrogen & $\mathrm{mg} \mathrm{dl}^{-1}$ & 2.8 & 2.9 & 1.7 & 0.5 \\
Ammonia & $\mu \mathrm{g} \mathrm{dl}^{-1}$ & $>1000$ & $>1000$ & $>1000$ & $>1000$ \\
$\mathrm{Na}$ & $\mathrm{mmol} \mathrm{l}^{-1}$ & 72.5 & 72.7 & 73.9 & 72.4 \\
$\mathrm{~K}$ & $\mathrm{mmol} \mathrm{l}^{-1}$ & 31.9 & 23.4 & 24.6 & 28.53 \\
$\mathrm{Cl}$ & $\mathrm{mmol} \mathrm{l}^{-1}$ & 41.6 & 47.5 & 46.2 & 45.3 \\
Specific gravity & & 1.034 & 1.012 & 10.19 & 10.16 \\
\hline
\end{tabular}

under polarized light closely resembled features that have been reported previously in studies on renal calcium deposition in turtles (Stacy et al. 2008, Jacobson et al. 2009) and monkeys (Skelton-Stroud \& Glaister 1994, Yanai et al. 1995). Calcium oxalate crystals stain with Alizarin Red S at a pH of 7.0 but not at a $\mathrm{pH}$ of 4.2. This differentiates calcium oxalate from calcium carbonate and calcium phosphate, both of which stain at pH 7.0 as well as 4.2 (Proia \& Brinn 1985). In addition, $2 \mathrm{M}$ acetic acid removes calcium carbonate and phosphate but leaves calcium oxalate. Treatment with $0.1 \mathrm{~N}$ hydrochloric acid removes calcium oxalate and calcium carbonate and phosphate. Further, examination of tadpole kidneys using HPLC showed the presence of oxalate in the affected tadpoles. From these findings, the crystals in the kidneys of tadpoles were identified as calcium oxalate.

In this study, tadpoles with severe abdominal distention showed large amounts of crystal deposition in the kidney. The ammonia levels in their coelomic fluid showed higher levels than the upper reference limit of plasma levels of vertebrates, typically less than $100 \mathrm{\mu g} \mathrm{dl}^{-1}$ in vertebrates (Conway \& Cooke 1939). Bullfrog tadpoles are ammonotelic animals, and as such they excrete nitrogenous wastes in the form of ammonia (Wright \& Wright 1996). High levels of ammonia in the coelomic fluid of affected tadpoles indicates a defect in ammonia metabolism, which in this case was presumably due to oxalate nephropathy.

Renal oxalosis or oxalate nephropathy in domestic animals is caused most frequently by ingestion of, or intoxication by, ethylene glycol. Consumption of oxalate-rich plants or plants colonized by oxalateproducing fungi, such as Aspergillus niger and A. flavus, can also cause renal oxalosis (Sanz \& Reig 1992, Rahman et al. 2013). Little has been reported on oxalate deposition in free-living wild animals. Ethylene glycol poisoning was described in a raccoon Procyon lotor, a polar bear Ursus maritimus, and a captive-bred released California condor Gymnogyps californianus (Amstrup et al. 1989, Murnane et al. 1995, Foley \& McBurney 2002). Oxalate deposition has been reported in koala Phascolarcotos cinereus, white-tailed deer Odocoileus virginianus, green turtle Chelonia mydas, desert tortoise Gopherus agassizii, baboon Papio ursinus, and Japanese macaque Macaca fuscata (Wyand et al. 1971, McConnell et al. 1974, Yanai et al. 1995, Stacy et al. 2008, Jacobson et al. 2009, Speight et al. 2013). In these cases, most animals were asymptomatic, and these occurrences were presumed to result from the ingestion of oxalate-rich plants. Wright (2001) reported that consumption of crickets fed on oxalate-containing plants was responsible for renal oxalosis in captive-breeding waxy frog Phyllomedusa sauvagii and relict leopard frog Rana onca (Wright 2001); however, reports regarding oxalate poisoning in free-living amphibians are lacking.

In this study, we tried to find the possible source of oxalate ingestion by the tadpoles. There were no sources of ethylene glycol in pond A, nor was there any evidence of Aspergillus infection. American bullfrog tadpoles are herbivorous and feed on plants and algae (Altig et al. 2007). Environmental analyses revealed the presence of oxalate in the fallen leaves and mud in pond A. Even though the source of oxalate in the present case remains unknown, it was most likely that the tadpoles ingested oxalate by feeding on sediments containing oxalate-containing plants.

The American bullfrog is native to North America. It has been introduced in several other countries and islands around the world, and is considered the most important pest in these regions. Recently, American bullfrogs have been widely suggested as infectiontolerant reservoirs for emerging infectious diseases, such as those caused by viral and fungal pathogens (Une et al. 2009). In the present study, edema was one of the findings in tadpoles with renal oxalosis, and it has also been observed in emerging ranaviral infection (Pessier 2009). This suggests the importance of obtaining a differential diagnosis for both diseases.

Acknowledgements. This work was supported by a research project grant awarded by Azabu University. We thank Dr. Ken-ichi Tamukai (Den-en-chofu Animal Hospital, Japan) for assistance with biochemical analysis and Dr. Toshio Kuroki (Kanagawa Prefectural Institute Microbiology, Japan) for valuable comments. 


\section{LITERATURE CITED}

Altig R, Whiles MR, Taylor CL (2007) What do tadpoles really eat? Assessing the trophic status of an understudied and imperiled group of consumers in freshwater habitats. Freshw Biol 52:386-395

Amstrup SC, Gardner C, Myers KC, Oehme FW (1989) Ethylene glycol (antifreeze) poisoning in a free-ranging polar bear. Vet Hum Toxicol 31:317-319

Conway EJ, Cooke R (1939) Blood ammonia. Biochem J $33: 457-478$

Foley P, McBurney S (2002) Ethylene glycol toxicosis in a free-ranging raccoon (Procyon lotor) from Prince Edward Island. Can Vet J 43:291-292

Jacobson ER, Berry KH, Stacy B, Huzella LM, Kalasinsky VF, Fleetwood ML, Mense MG (2009) Oxalosis in wild desert tortoises, Gopherus agassizii. J Wildl Dis 45:982-988

Marsh IB, Whittington RJ, O'Rourke B, Hyatt AD, Chisholm O (2002) Rapid differentiation of Australian, European and American ranavirus based on variation in major capsid protein gene sequence. Mol Cell Probes 16:137-151

McConnell EE, Basson PA, de Vos V, Myers BJ, Kuntz RE (1974) A survey of diseases among 100 free ranging baboons (Papio ursinus) from the Kruger National Park. Onderstepoort J Vet Res 41:97-167

Murnane RD, Meerdink G, Rideout BA, Anderson MP (1995) Ethylene glycol toxicosis in a captive-bred released California condor (Gymnogyps californianus). J Zoo Wildl Med 26:306-310

> Pessier AP (2009) Edematous frogs, urinary tract disease, and disorders of fluid balance in amphibians. J Exot Pet Med 18:4-13

Proia AD, Brinn NT (1985) Identification of calcium oxalate crystals using alizarin red S stain. Arch Pathol Lab Med 109:186-189

Editorial responsibility: Lee Skerratt, Townsville, Queensland, Australia
Rahman MM, Abdullah RB, Wan Khadijah WE (2013) A review of oxalate poisoning in domestic animals: tolerance and performance aspects. J Anim Physiol Anim Nutr (Berl) 97:605-614

Sanz P, Reig R (1992) Clinical and pathological findings in fatal plant oxalosis. Am J Forensic Med Pathol 13: 342-345

Skelton-Stroud PN, Glaister JR (1994) Oxalate nephrosis in Macaca fascicularis. Lab Anim 28:265-269

Speight KN, Boardman W, Breed WG, Taggart DA, Woolford L, Haynes IJ (2013) Pathological features of oxalate nephrosis in a population of koalas (Phascolarctos cinereus) in South Australia. Vet Pathol 50:299-307

Stacy BA, Santoro M, Morales JA, Huzella LM and others (2008) Renal oxalosis in free-ranging green turtles Chelonia mydas. Dis Aquat Org 80:45-49

- Une Y, Sakuma A, Matsueda H, Nakai K, Murakami M (2009) Ranavirus outbreak in North American bullfrogs (Rana Catesbeiana), Japan, 2008. Emerg Infect Dis 15: 1146-1147

Wright KM (2001) Nutritional disorders. In: Wright KM, Whitaker BR (eds) Amphibian medicine and captive husbandry. Krieger Publishing Company, Malabar, FL, p 73-87

Wright PM, Wright PA (1996) Nitrogen metabolism and excretion in bullfrog (Rana catesbeiana) tadpoles and adults exposed to elevated environmental ammonia levels. Physiol Zool 69:1057-1078

Wyand DS, Langheinrich K, Helmboldt CF (1971) Aspergillosis and renal oxalosis in white-tailed deer. J Wildl Dis 7:52-56

> Yanai T, Wakabayashi T, Masegi T, Ishikawa K, Yamazoe K, Iwasaki T, Ueda K (1995) Subclinical renal oxalosis in wild-caught Japanese macaque (Macaca fuscata). J Comp Pathol 112:127-131

Submitted: May 26, 2015; Accepted: September 30, 2015 Proofs received from author(s): October 19, 2015 